\title{
PRODUCTOS FORESTALES NO MADEREROS DEL BOSQUE: UN SIGNIFICATIVO APORTE ECONOMICO A LA EMPRESA FORESTAL.
}

Alejandro González EUFORES agonzalez@eufores.com.uy y Carolina Sans Depto. Producción Forestal y Tecnologia de la Madera. Facultad de Agronomia, urrest@adinet.com.uy

\section{RESUMEN}

El uso múltiple comprende los productos y servicios derivados de los bosques, dentro de los cuales el más conocido y valorado es la madera, materia prima fundamental para distintas industrias. Además, y especificamente en Uruguay, los bosques implantados están abiertos al pastoreo. La apicultura es otra actividad en creciente auge. Los hongos, los aceites esenciales y los frutos, son entre otros, algunos de los productos que se extraen de los bosques y son comercializados en el país generando ingresos durante parte o todo el ciclo del bosque. Entre los servicios que brindan los bosques se encuentran las funciones ecológicas, culturales, educativas, recreativas o paisajisticas. Se destacan entre las primeras, la conservación de suelos, la regulación de temperatura y vientos, fijación de dunas, la fijación de $\mathrm{CO}_{2}$.

El presente trabajo tiene por objetivo conocer y cuantificar los beneficios no maderables de los bosques. Se realiza una descripción general de los distintos usos que se lleva a cabo en los bosques del pais y se detalla y cuantifica los múltiples usos y actividades que se realiza en las masas boscosas de Eucalyptus spp. de la empresa EUFORES S.A en la región litoral oeste. Se destaca la importancia económica y social que los mismos tienen para la empresa en particular y el Uruguay en general. Los valores obtenidos sobre el silvopastoreo, la apicultura, los hongos y la fijación de $\mathrm{CO}_{2}$. Se presenta a su vez una serie de recomendaciones relativas al mejor uso múltiple del bosque que surgen de este estudio en particular.

\section{SUMMARY}

Multiple use of forest encompasses the goods and services derived from forests, being timber the best known and valuable product, the raw material for different industries. Besides that, and specifically in Uruguay, planted forests are open for grazing. Apiculture is another increasing activity in forest lands. Mushrooms, oils and fruits are, among others, some of the products derived from forests that are commercialised in the country and generate revenues during all or part of forest rotation. Among their services are the ecological, cultural, educational, recreational and landscaping functions. Examples of the first function are, conservation of soils, temperature and wind regulation, dunes fixation and $\mathrm{CO}_{2}$ sequestration.

The objective of this study is to know and quantify the benefices of non wood forest products and forest activities. A general description of different uses of country forests is presented and a also a detailed description and quantification of multiple uses and activities of Eucalyptus spp. forest plantations of Eufores enterprise in the west region of Uruguay. The 
results of the study show the economic and social importance of non wood forest products and activities particularly for the enterprise as well as for the country in general. Data obtained from grazing, apiculture, mushrooms and carbon sequestration are presented and recommendations for the best multiple forest use are given.

\section{INTRODUCCION}

Los primeros bosques implantados en Uruguay tuvieron por objetivo el abrigo y sombra para el ganado bovino y ovino (parición y post- esquila), la protección contra los vientos (en cultivos frutales) y la fijación de dunas en la costa atlántica hacia fines del siglo XIX.

Si bien el concepto de uso múltiple del bosque estaba implícito en la utilización con fines de pastoreo, no ha sido práctica común incluirlo en la valoración económica como así tampoco los productos forestales no madereros.

Es recién en la última década que comienza a tomar fuerza el aprovechamiento del bosque como proveedor de toda una serie de bienes y servicios por parte de las empresas forestales, constituyéndose además en objeto de investigación para las instituciones encargadas del tema.

Tomar en cuenta otros productos de los bosques implantados y nativos, como las pasturas del sotobosque y las porciones de campo no forestado (para uso de pastoreo ovino o bovino), las hojas (para extracción de aceites esenciales), los hongos comestibles, o bien la fijación de $\mathrm{CO}_{2}$ es muy importante al definir las potenciales estrategias macro y microeconómicas de una empresa forestal.

En el ámbito internacional existen diferentes trabajos que recogen las utilidades y usos de los productos no madereros del bosque, sin embargo en el país son pocas las referencias al respecto, por lo que este trabajo constituye uno de las primeras experiencias de valoración en el tema.

\section{OBJETIVOS}

El presente trabajo tiene por objetivo general conocer los beneficios no maderables de los bosques y por objetivos especificos los siguientes:

Ampliar el conocimiento sobre los productos no maderables derivados de los bosques.

Cuantificar los productos y servicios de los bosques implantados.

Promover el uso múltiple de los bosques en las empresas forestales y la interacción entre estas y las comunidades locales sin distinción de género.

Propender a la difusión de usos alternativos del bosque. 


\section{ANTECEDENTES GENERALES}

Las explotaciones forestales del Uruguay han centralizado la visión económica de la explotación del recurso bosque en la utilización de la madera. Como se mencionó líneas arriba, las primeras masas boscosas implantadas en el pais tenian por objetivo el abrigo y sombra para el ganado, la protección contra vientos principalmente en cultivos frutales y la fijación de dunas.

Actualmente, y promovido por la segunda Ley forestal ( $\mathrm{N}^{\circ} 15939$, del año 1987), existe un gran desarrollo forestal en el país, con algo más de 700 mil hectáreas forestadas con especies exóticas (eucaliptos, pinos y salicáceas en menor proporción), cuyo objetivo es la producción de madera como materia prima para la producción de celulosa y papel, aserrio y columnas, entre otros. Dentro del Género Eucalyptus las especies más plantadas son E. globulus (ssp. globulus, maidenii y, en menor porcentaje, bicostata) y E. grandis. Dentro del género Pinus, las especies más importantes son P. taeda y P. elliotti.

Las principales masas forestales están concentradas en tres grandes zonas, según grupos de suelos denominados de prioridad forestal por la mencionada ley. Los suelos en estas zonas se caracterizan por ser arenosos, profundos, o bien, rocosos, de baja fertilidad, y bajo indice de productividad para los usos tradicionales (agricultura y ganaderia) de la tierra, por lo cual no se trata de un cultivo de competencia.

Las densidades de plantación son variables según género y especie utilizada y destino de los bosques. Las densidades iniciales de los bosques de eucaliptos para producción de pasta de celulosa oscilan entre 1100 y 1600 árboles por hectárea. Los crecimientos medios y turnos de cosecha varían según los diferentes sitios y objetivos de producción. E. globulus y E. grandis, con crecimientos medios anuales (IMA) muy heterogéneos, que van desde los 12 a los $25 \mathrm{~m}^{3} / \mathrm{ha}$, se cosechan, en su mayoria, entre los 8 y 12 años de edad.

En los últimos años, otros usos que generan o pueden generar ingresos económicos directos o indirectos, han comenzado a tomar importancia en las empresas que se dedican al rubro forestal (Rowe, R. S.; Mc Cormack, R. J., 1968).

En el Cuadro $\mathrm{N}^{0} 1$ se resume los principales usos identificados en el pais.

\section{Cuadro $\mathrm{N}^{\circ} 1$. \\ USO MULTIPLE DE LOS BOSQUES EN URUGUAY}

\begin{tabular}{|l|l|}
\hline FUNCIONES & PRODUCTOS /SERVICIOS \\
\hline Productivas & Silvopastoreo \\
\hline & Miel \\
\hline & Hongos \\
\hline Ecológicas & Aceites esenciales, resinas \\
\hline & Conservación de suelos \\
\hline & Regulación de temperatura, vientos \\
\hline & Fijación de dunas \\
\hline & Conservación de la diversidad biologica \\
\hline Socio/culturales & Fijación de CO, \\
\hline & Pedagógico \\
\hline & Paisajistico \\
\hline & Recreativo, ecoturismo \\
\hline & Cultural \\
\hline
\end{tabular}




\section{Funciones Productivas}

\section{Silvopastoreo}

El pastoreo de bosques con ganado bovino se realiza a partir de los 18 a 24 meses de implantadas las masas (dependiendo del desarrollo del bosque) y hasta la cosecha del mismo (8 a 12 años). Durante la preparación de los terrenos, la plantación y los primeros estadios de crecimiento del bosque, las producciones son incompatibles (el ganado se "rasca" contra los árboles provocando que estos se quiebren, perdiéndose por lo tanto ejemplares o al menos parte del crecimiento de los mismos).

La carga animal en los campos forestados depende de varios factores, entre los que destacan:

- Especie forestal: Dentro del género Eucalyptus hay una marcada diferencia entre las dos especies más plantadas por la arquitectura y el desarrollo de la copa y la conformación del follaje. En montes de E. globulus el cierre del dosel se produce más tarde comparado con E. grandis, e incluso muchas veces no se cierra totalmente, con lo cual durante todo el turno de producción subsiste un tapiz vegetal bajo los árboles. En plantaciones de $E$. grandis muchas veces el tapiz desaparece bajo la sombra y el mantillo producido por los árboles.

- Silvicultura aplicada: El marco de plantación es determinante en la producción de forraje a lo largo del turno de producción, por ejemplo para una misma densidad de plantación (ej. 1250 árboles/ ha.) la producción de forraje será mayor en aquella plantación donde mayor sea la distancia entre filas (un espaciamiento de 4 metros generará más cobertura de gramineas y otras especies en la entrefila que un espaciamiento de 3 metros).

- Tipo de suelo: La fertilidad natural de los suelos determina diferencias en la producción de forraje (diferencias en la producción anual media de materia seca), con lo cual la carga animal depende en gran medida del tipo de suelo en cuestion.

- Epoca del año: Asociado con el tipo de suelo, los ciclos de las pasturas pueden ser perennes, estivales o invernales por lo que la carga animal variará según la disponibilidad en cada momento.

Las experiencias de silvopastoreo con ganado ovino son más recientes. Los animales pueden ingresar al bosque a los 6 meses (en promedio), dado el comportamiento de las ovejas de no recostarse sobre los árboles y su menor tamaño que también minimiza posibles perjuicios. Si bien en muchos casos es importante para el productor agropecuario tener la posibilidad de usar campos forestados, en el caso del ganado ovino se presenta la dificultad al momento de juntar las majadas dentro del bosque pues a veces se producen pérdidas de algún animal enfermo entre los árboles. La carga animal dependerá en este caso de los mismos factores mencionados para el ganado bovino. 


\section{Apicultura}

Si bien la compatibilidad entre las producciones maderera y apicola es compleja, principalmente por el riesgo de incendios forestales y el riesgo potencial a la salud por picadura de los insectos a los trabajadores forestales, se ha comenzado a realizar algunas pruebas previo "protocolo" de acción dentro de los predios forestales. Asi, se trata de aprovechar una de las cualidades de los eucaliptos que es la de ser, en general, buen productor de néctar y polen, lo que permite una buena producción de miel. De acuerdo a la información recabada, la producción por colmena en bosques de E. grandis aumenta de $30-35 \mathrm{Kg}$. a alrededor de $60 \mathrm{Kg}$. por colmena.

La especie de abeja más frecuente en Uruguay es Apis mellifera. El complemento apicultura tradicional y forestación podria ser de gran impacto, pues permitiría, además de aumentar los volúmenes de producción por cosecha, incrementar el número de las mismas dado que en Uruguay, luego de las cosechas de verano sobre pasturas (semilleros), las colmenas se reducen y dejan de producir por la inexistencia de flores disponibles. Por lo tanto, las especies de eucaliptos que florecen en otoño podrían suministrar las flores para que las abejas sigan trabajando. Para ello, los volúmenes de floración deben ser importantes o de lo contrario el insecto reduce la producción y la misma deja de ser rentable.

En Uruguay, la floración del género Eucalyptus es variable según la especie, por ejemplo, $E$. grandis florece a edad más temprana que $E$. globulus, lo que favorece a los apicultores en la producción de miel Recientemente se promulgó una ley $\left(\mathrm{N}^{\circ} 17115\right)$ que limita los subsidios a la producción (forestal u otras) a los proyectos tendientes al desarrollo apícola. El artículo 8 de esta ley expresa que "aquellos proyectos de explotación, agrícola, pecuaria o forestal que aspiren a ser beneficiados por subsidio público, incluyendo crédito en condiciones preferenciales, exoneraciones impositivas o arancelarias especificas, deberán incluir una adecuada explotación del potencial apicola vinculado al emprendimiento". Esta ley no ha sido aún reglamentada por lo que lo dispuesto en la misma todavia no se aplica en la práctica.

Hongos

El principal uso comercial de los hongos es para alimentación (Deschamps, J. R., 2002). Si bien en el pais el tema ha sido hasta ahora poco considerado, se destacan claramente dos lineas de desarrollo en el ámbito forestal. Por un lado, en la costa este del pais, mayoritariamente en bosque de pinos ( $P$. pinaster), personas que viven en la zona recolectan hongos que luego venden a orillas de la ruta Interbalnearia, ya sea al natural o en conserva. Por otro lado, en los últimos años ha tenido gran desarrollo la producción del hongo Lentinus edodes, "Shiitake" u "hongo japonés". Se trata de un hongo saprofito que puede ser cultivado sobre troncos de eucaliptos procedentes de podas, raleos o residuos de cosecha. El proceso de producción consiste en perforar los troncos (de diámetros comprendidos entre 10 y $15 \mathrm{~cm}$. y de 1 a $1,20 \mathrm{~m}$ de largo), con contenidos iniciales de humedad entre 35 y $55 \%$, e inocularlos. A los 4-6 meses de realizada la inoculación con el micelio del hongo se procede a la cosecha. Durante ese periodo la temperatura debe mantenerse entre $22-25^{\circ} \mathrm{C}$. El rendimiento por tronco es variable, oscilando entre 0,75 y 1 kilogramo. Luego de realizada la cosecha la conservación se realiza a bajas temperaturas 
$\left(0^{\circ}\right.$ a $\left.2^{\circ} \mathrm{C}\right)$ y altos contenidos de humedad ( 85 a $\left.95 \%\right)$, por un periodo máximo de alrededor de 15 dias.

\section{Aceites Esenciales y Resinas}

La producción de aceites esenciales en el sector forestal uruguayo se basa en el uso de las hojas de $E$. globulus ssp. globulus que quedan luego de la cosecha forestal, las que se procesan con destiladores especiales. Una hectárea de $E$. globulus maduro rinde alrededor de $9.000 \mathrm{~kg}$. de hojas. El rendimiento en aceite se estima entre el 1,2 y $1,7 \%$ del peso de las hojas.

Respecto de las resinas, $P$. elliottii es la especie más adecuada. Se debe tener en cuenta la reducción que se produce en crecimiento con el proceso de resinación, con lo cual es imprescindible la cuantificación económica del proceso. Han sido muy pocos y a escala experimental los trabajos de de este tipo y han tenido lugar en los años 30 el primer ensayo y a fines de la década del 70 otra de las experiencias.

\section{Funciones Ecológicas}

\section{Conservacion de Suelos}

Los árboles inciden en el escurrimiento superficial del agua de lluvia y, por lo tanto, en la disminución del arrastre de particulas del suelo. Esto hace que se reduzca la erosión difusa. Es este un aspecto muy importante que se toma en cuenta al momento de diseñar las parcelas y en la época de preparación del terreno dedicado a forestación. La legislación vigente contempla estos aspectos a efectos de controlar los posibles impactos al suelo por mal manejo de los mismos (V Jornadas Técnicas,1989).

Regulación de la Temperatura, Viento y Otros

Las masas boscosas regulan la temperatura, actuando sobre la radiación solar total que ingresa al sistema, parte de la misma es absorbida por los árboles y se produce sensible disminución del albedo. Tanto los bosques nativos como los plantados actúan como resguardo para el ganado o cultivos contra el frio, viento o sol ("bosques de abrigo para parición y post esquila y bosques de sombra" para el ganado; "cortinas rompevientos" para protección de cultivos citricolas, viveros, etc).

\section{Fijación de Dunas}

En la costa este los bosques de $P$. pinaster (pino marítimo) han sido fundamentales en los procesos de fijación de dunas.

Conservación de la Diversidad Biológica

Estudios realizados (Prigioni y Villalba, 2005) en bosques de eucaliptos en el litoral oeste uruguayo dan por resultado que la fauna nativa se mantiene tanto dentro como en la 
periferia del bosque, en manchas y corredores de praderas no cultivadas (campo natural), bosques nativos (ribereños o de galerias), palmares y bañados. Es importante resaltar que la Ley Forestal No 15939 prohibe la corta o cualquier otra operación que atente contra la supervivencia del monte nativo en todo el territorio nacional.

Fijación de $\mathrm{CO}_{2}$

Además de la función ecológica, la fijación de $\mathrm{CO}_{2}$ por los bosques adquiere valor económico. Se han iniciado recientemente en el país los primeros estudios tendientes a cuantificar la biomasa aérea forestal y captación de carbono en plantaciones de eucaliptos (Stevens, James A. y Montgomery Claire A., 2002).

\section{Funciones Social y Cultural}

\section{Educación}

Existen en el pais varios ejemplos de actividades de educación ambiental e interpretación en áreas de bosques implantados (senderos de interpretación en Parque Anchorena, Parque Santa Teresa, Parque de Vacaciones para Funcionarios de UTE-ANTEL) si bien el mayor número de estas actividades se realizan en áreas de bosque nativo.

\section{Paisaje}

Los diferentes tipos de bosques nativos asi como los bosques implantados componen junto a la topografia, las actividades del hombre y los cursos de agua, diferentes paisajes que marcan la identidad de los sitios donde se ubican.

\section{Recreación y Ecoturismo}

En el pais, el uso temporario del bosque industrial como área recreativa no se ha dado hasta el momento pero existen áreas boscosas, algunas de ellas parquizadas, dedicadas a actividades de camping o pic nic. También se destacan los bosques costeros cuyo objetivo original fue la fijación de dunas que desde hace ya varias décadas cumplen fundamentalmente un rol recreativo (Sans, C., 1992).

\section{Cultura}

En ocasiones los predios forestales albergan monumentos históricos. Su protección y cuidado pasa a ser responsabilidad de la empresa o propietario del lugar como la "Tapera de Darwin" en tierras forestadas de la Empresa EUFORES S.A. en la zona de Bequeló en el Departamento de Soriano, o las ruinas del viejo saladero ingles de Mbopicuá sobre las costas del Rio Uruguay en las cercanías de Fray Bentos en el Departamento de Río Negro. 


\section{MATERIAL Y METODO}

El estudio de caso que se presenta está basado en un trabajo de tesis realizado a escala nacional (Antón, sin publicar). Se recabó información y se llevaron a cabo entrevistas al nivel de una empresa forestal. Los datos obtenidos fueron analizados y procesados para luego proceder a la evaluación económica de los diferentes productos no madereros identificados.

Para la valoración económica se tuvo en cuenta los ingresos directos de dinero que genera el uso de la masa boscosa, como así también los ingresos indirectos, como por ejemplo por reducciones en las aplicaciones de químicos.

\section{ESTUDIO DE CASO: LA EMPRESA EUFORES}

La empresa forestal EUFORES SA tiene sus campos mayoritariamente en el litoral oeste uruguayo, en los departamentos de Rio Negro, Soriano y Paysandú, sobre suelos arenosos y en menor proporción en el sur- este, sobre suelos rocosos.

Las plantaciones están compuestas, en mayor área, por E. globulus ssp. globulus, y en menor porcentaje por E. globulus ssp. maidenii, E.globulus ssp. bicostata, E. grandis, E. dunnii, Pinus spp y algo de Salicáceas, con densidades de plantación que varian entre 1100 y 1500 árboles por hectárea y turnos de cosecha que van de los 8 a 10 años. Se realizan tareas de mantenimiento durante los primeros estadios de crecimiento para eliminar las pasturas que sean competencia para el bosque. Luego de cosechado el bosque, parte de los predios son reforestados (plantación en entrefilas de tocones originales) y parte se destina a segundo turno (manejo de rebrotes). La decisión se toma en función del estado anterior del bosque (densidad, aspecto sanitario) y disponibilidad de plantas, entre otras.

El uso múltiple de las àreas boscosas y la obtención de productos forestales no madereros constituyen un objetivo importante para la empresa, aunque la finalidad principal es la producción de madera pulpable para exportación. A continuación se describe y evalúa los diferentes usos y productos no madereros provenientes de los bosques.

\section{Silvopastoreo con Ganado Bovino}

El pastoreo de los bosques con ganado bovino se realiza a partir de los 18 a 24 meses de implantadas las masas, según el desarrollo de los árboles, permaneciendo los animales hasta la cosecha del mismo. Es determinante la evaluación técnica de cuándo, qué tipo de ganado (peso vivo del animal) y carga (unidades ganaderas por hectárea) ingresará al predio, ya que una mala decisión (cuando los árboles aủn no tienen el desarrollo óptimo) significará posteriores pérdidas de ejemplares o retraso del crecimiento por daños de animales al recostarse a los árboles (Empresa Secco Hnos., 1998. Evaluación de Manejo Silvopastoril. Experiencia Nacional, Informe). 
Ingresos Directos

En el Cuadro $\mathrm{N}^{\circ} 2$ se indica los parámetros a tener a considerar para cuantificar los ingresos por silvopastoreo en bosques de E. globulus ssp. globulus.

\section{Cuadro $\mathrm{N}^{\circ} 2$ \\ PARAMETROS A CONSIDERAR EN LA CUANTIFICACIÓN DE INGRESOS POR SILVOPASTOREO}

\begin{tabular}{|c|c|c|}
\hline Parámetros & Valor & Observaciones \\
\hline Área forestada (media) & $65 \%$ del total & $\begin{array}{l}\text { Se produce un } 10 \% \text { de pasturas en un campo } \\
\text { forestado respecto al campo natural. }\end{array}$ \\
\hline $\begin{array}{l}\text { Oferta anual de Materia } \\
\text { Seca }\end{array}$ & $1245 \mathrm{~kg} . \mathrm{MS} / \mathrm{ha} \mathrm{(1)}$ & $\begin{array}{l}\text { Producción anual de Materia Seca promedio, en } \\
\text { campo natural (área sin forestar): } 3000 \mathrm{Kg} \text { MS/ha. }\end{array}$ \\
\hline Consumo de 1 UG & 3814 kg. MSiaño (2) & $\begin{array}{l}\text { Se estima un consumo potencial del vacuno de } 2.75 \% \\
\text { del peso vivo (promedio) }\end{array}$ \\
\hline Dotación promedio & 0,33 UG/ha & Oferta de forraje / consumo de UG $=1245 / 3814$ \\
\hline
\end{tabular}

Nota: (1) $3000 \mathrm{Kg} .{ }^{*} 0.35$ (área no forestada) $+3000 \mathrm{Kg} .{ }^{*} 0,1^{*} 0.65$ (área forestada)

(2) $380 \mathrm{Kg}$ peso vivo (animal adulto) $2,75 \% * 365$ dias

Esta dotación promedio de ganado bovino (0,33 UG/ha) puede diferenciarse claramente en dos realidades distintas a lo largo del turno del bosque. En los primeros 3 años de ingreso de ganado (24 meses al $5^{\circ}$ año) la dotación puede ascender a $0,4 \mathrm{UG} / \mathrm{ha}$, mientras que en los últimos 3 a 4 años (hasta el $8^{\circ}$ ó $9^{\circ}$ año) la dotación baja a 0,3 UG/ha. Esto es debido a la disponibilidad de forraje a lo largo del periodo, a medida que los árboles crecen se produce un mayor "cierre de copa" y las pasturas dentro del bosque disminuyen en cantidad y calidad. Una renta media actual en campos forestados es de alrededor de 0,95 US \$/ha/mes para los primeros tres años y de 0,65 US \$/ha/mes para los últimos tres a cuatro años, con lo cual puede estimarse un ingreso anual medio durante 7 años (desde los 24 meses hasta cosecha, suponiendo que la misma se efectúe al $9^{\circ}$ año) de 9,4 US $\$ /$ ha/año $\left(0,78\right.$ US $\$$ promedio/ha/mes* 12 meses). En la Figura $N^{0} 1$ se muestra el ingreso anual por pastoreo bovino.

Ingresos Indirectos

Se refiere a la reducción por parte del productor forestal en la aplicación de tratamientos quimicos al bosque. El ingreso de ganado evita al menos la aplicación de un tratamiento en entre filas de plantación con glifosato que es utilizado para eliminar las pasturas que compiten con los árboles en los primeros años de crecimiento y que limitan o retrasan el crecimiento de los mismos. Actualmente el costo de una aplicación de glifosato en entre filas es de 13 US $\$ /$ ha, a lo que se suma el costo del producto (2 US \$/L). Dado que la aplicación se realiza a razón de $3 \mathrm{~L} / \mathrm{ha}$ (promedio), el ahorro final es de alrededor de 19 US \$/ha 


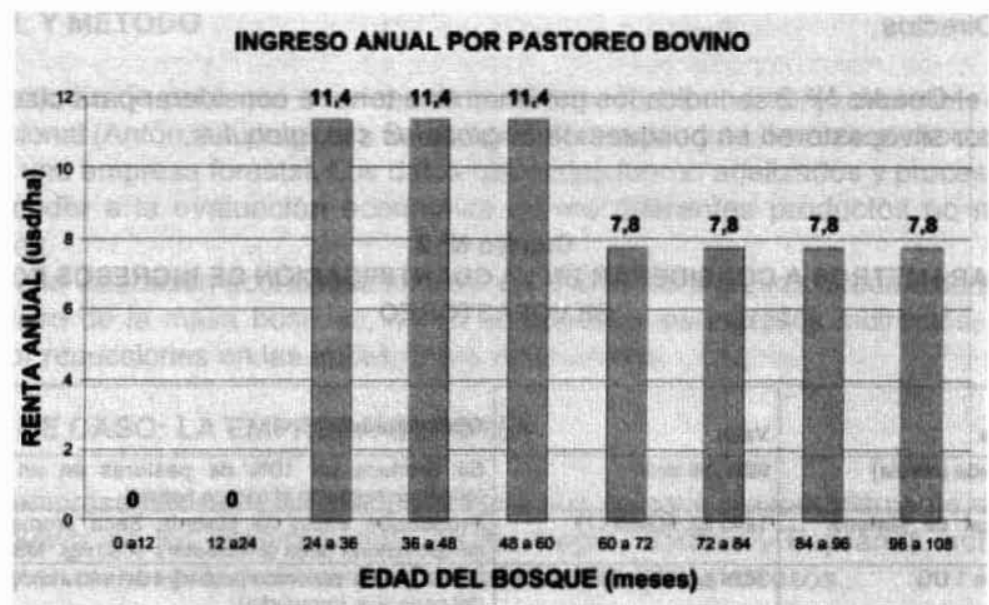

Figura $\mathrm{N}^{\circ} 1$.

INGRESO ANUAL POR PASTOREO BOVINO

\section{Silvopastoreo con Ganado Ovino}

Se está realizando actualmente experiencias piloto con ingreso de lanares en los bosques desde los 6 meses de implantados y hasta el ingreso a los mismos de ganado bovino, que como fue mencionado anteriormente se produce entre los 18 y 24 meses.

Ingresos Directos

Actualmente no se cobra renta al productor agropecuario para el uso de los campos forestados con ganado ovino. Se pacta el cobro de rentas a partir del ingreso de ganado bovino y exclusión del ovino. Los beneficios económicos para el productor forestal se dan por los ahorros en la aplicación de químicos tanto en la entre fila como en la fila de plantación para eliminar las pasturas.

Ingresos Indirectos

El ingreso de ovinos en los bosques a los 6 meses permite reducir como mínimo una aplicación de glifosato en la fila. El costo de la misma es de 16 US \$/ha (aplicación manual con mochilas). A ello se suma el costo del producto que es de 2 US $\$ / L$ a razón de $1 \mathrm{~L} / \mathrm{ha}$. En total, el ahorro de una aplicación de herbicida en la fila de plantación es de alrededor de 18 US \$/ha. En referencia al control en la entrefila de plantación el ganado ovino evita por lo menos de dos a tres aplicaciones de glifosato. Como se explicó para el ganado bovino, el costo de una aplicación de glifosato en entre filas es de 13 US $\$$ /ha y el costo del producto es de 2 US $\$ / L$. Dado que la aplicación se realiza a $3 \mathrm{~L} / \mathrm{ha}$, el ahorro final es de aproximadamente 19 US \$/ha. El ahorro total estimado en la aplicación de quimicos con el ingreso de ovinos, considerando una aplicación en la fila y dos en la entre fila es de unos 56 US \$/ha. 


\section{Producción de Miel}

Si bien actualmente no se están realizando experiencias de producción de miel, existen propuestas para realizar pruebas piloto en predios forestados con $E$. grandis. Los productores apícolas colocarán las colmenas en la masa boscosa por el periodo de floración de los árboles (3 a 4 meses), manejándose según protocolos de acción dentro del bosque. En promedio se hace referencia a una tarifa de 4 a 5 US \$/colmena/mes, con una densidad media de 4 colmenas por hectárea, lo que determina un precio total de entre 16 y 20 US $\$$ / ha/mes. El ingreso anual seria de alrededor de 72 US \$/ha, considerando que solo se utilice el bosque durante el periodo de floración (4 meses máximo* 18 US \$/ha/mes promedio).

\section{Producción de Hongos}

Promovida por la empresa EUFORES S.A., se desarrolla en la ciudad de Fray Bentos desde el año 2003 una cooperativa local de productores de Shiitake. El suministro de los troncos (restos de la cosecha forestal); el lugar físico para el cultivo del hongo y el asesoramiento técnico (inicialmente por experto japonés) están a cargo de la empresa. De esta forma se logra generar mano de obra para pobladores, hombres y mujeres, desempleados o subempleados de la ciudad de Fray Bentos, quienes han encontrado de esta forma un ingreso económico. Los rendimientos del cultivo coinciden con los promedios mundiales de alrededor de æa $1 \mathrm{~kg}$. de Shiitake por tronco. El costo de producción total estimado, considerando una producción base de 1500 troncos, es de unos 2,3 US $\$ / \mathrm{kg}$. Esto incluye los costos de inoculación (1,26 US $\$$ ), incubación- cosecha $(0,64$ US $\$$ ) y postcosecha $(0,4$ US \$). El precio al público en la ciudad de Fray Bentos es de 3 US $\$ / \mathrm{kg}$.

\section{Aceites Esenciales}

Como se mencionó anteriormente, la producción de aceites esenciales se da a través del uso de hojas de E. globulus ssp. globulus que quedan como residuos de la cosecha forestal. Si bien EUFORES no ha comenzado aún a desarrollar el tema, está analizando una propuesta concreta de gestión donde las hojas, a través de destiladores especiales, serían aprovechadas en el propio bosque. La extracción de la esencia se realizaria por cohobación, durante 3 ó 4 horas las hojas son sometidas al paso de vapor que se desplaza por una tubería y es expulsado por cañerias sumergidas en agua fria y se condensa como un líquido compuesto por agua y aceite, que se separa posteriormente por diferencias de densidad. Si bien esto no generaría ingresos, al menos al principio, el beneficio para la empresa estaria dado por la eliminación de gran parte de los residuos de la cosecha forestal lo que facilitaria los tratamientos silvícolas de segundo turno, con la reducción en los costos de los mismos.

\section{Fijación de $\mathrm{CO}_{2}$}

Un equipo de investigación del Departamento de Producción Forestal y Tecnologia de la Madera de la Facultad de Agronomía realizó a través de un Convenio con Eufores un estudio de cuantificación de la biomasa aérea forestal en plantaciones de $E$. globulus en el litoral oeste uruguayo (patrimonio forestal de EUFORES) como estudio previo para la 
aplicación de modelo $\mathrm{CO}_{2} \mathrm{Fix}$ que permite el cálculo de carbono secuestrado. Los resultados del trabajo de investigación son resumidos en el Cuadro $\mathrm{N}^{\circ} 3$.

Cuadro 3.

PRODUCCION DE MATERIA SECA- PROMEDIO ANUAL

\begin{tabular}{|c|c|c|c|c|c|}
\hline ZONAS & ALGORTA & SORIANO & TRES BOCAS & QUEBRACHO & $\begin{array}{c}\text { LITORAL } \\
\text { PROMEDIO }\end{array}$ \\
\hline MAT. SECA (tha) & 11.38 & 15.48 & 15.42 & 10.93 & 12.98 \\
\hline
\end{tabular}

Aproximadamente la mitad de la materia seca total corresponde a carbono $(5,66 \mathrm{t}$ de $12,98 \mathrm{t}$ ). Los resultados del estudio establecen que la fijación anual media de $\mathrm{CO}_{2}$ para los bosques de $E$. globulus en el litoral uruguayo es de 20,71 toneladas $\mathrm{CO}_{2} /$ ha / año. Desde un punto de vista ecológico y a modo de ejemplo, durante el periodo 2000-2004 el patrimonio forestal de EUFORES en Uruguay a través de la captación de $\mathrm{CO}_{2}$ permitiria anular las emisiones de $\mathrm{CO}_{2}$ de la totalidad de los vehiculos $0 \mathrm{Km}$. que salieron al mercado en ese periodo.

Otro aspecto interesante es que en promedio cada uruguayo emite a la atmósfera una tonelada de $\mathrm{CO}_{2}$ al año. Si una hectárea de eucaliptos fija alrededor de $21 \mathrm{t}$. de $\mathrm{CO}_{2}$ al año, y la densidad media de plantación en el litoral es de 1300 árboles por hectárea, se necesita 62 árboles para anular las emisiones de $\mathrm{CO}_{2}$ de una persona cada año. Desde un punto de vista económico, se afirma que el precio de mercado para el carbono fijado por los bosques estaria en los 10 US \$/t. de $\mathrm{CO}_{2}$ fijada. Considerando que se fijan anualmente $21 \mathrm{t}$., los ingresos por concepto de fijación de $\mathrm{CO}_{2}$ serian de unos 210 US \$ por hectárea y año.

El Mecanismo de Desarrollo limpio (MDL), establecido por el Protocolo de Kyoto sobre Cambio Climático, acepta proyectos de forestación y reforestación (A/R) en paises en desarrollo como beneficiarios de pago por fijación de carbono siempre que cumplan con diversos requisitos. Entre estos destaca el principio de la adicionalidad, esto es que la captura o fijación de carbono sea adicional a la que se produciria sin este pago. EUFORES está estudiando las condiciones bajo las que algunas de sus nuevas plantaciones podrian ser beneficiarias de estos pagos, posiblemente en suelos marginales a la actual actividad forestal, suelos degradados que requieren recuperación u otros casos.

\section{Conservación de la Diversidad Biológica}

La empresa EUFORES S.A. posee dos áreas de conservación de fauna y flora. Santo Domingo en el norte de Paysandú y Mbopicuá, un reservorio de flora y estación de cria, en las cercanias de la ciudad de Fray Bentos.

La prohibición de la caza y la conservación de la flora nativa son principios importantes para la empresa, que los aplica en todas las áreas. En el establecimiento Santo Domingo se ha reportado (Prigioni y Villalba, 2005) alrededor de 160 especies de aves (cerca del $35 \%$ de todas las aves del pais), además de murciélagos (de las palmeras y vampiro), armadillos (mulita, tatú, peludo), zorro gris, zorrillo, hurón, mano pelada, lobito de río, gato montés, 
roedores (nutria, apereá, carpincho, tucu- tucu), exóticas (ciervo axis, jabali, liebre), reptiles (tortugas, lagartos, lagartijas, yacaré), ofidios, anfibios (sapos y ranas), entre otros. Además, se lleva a cabo un plan de recuperación del Palmar, especificamente de la palma Butiá Yatay, que se encuentra en los departamentos de Paysandú y Rio Negro. Las áreas naturales de esta palmera han disminuido considerablemente en los últimos años debido a que los campos donde se encuentran están sujetos a pastoreo y el rodeo vacuno come los nuevos ejemplares que nacen cada año.

En Mbopicua existe una estación de cria donde se reproducen y crecen especies de fauna nativa en peligro de extinción como el yacaré, mano pelada, pecari de collar o aves como el cardenal amarillo o el rey del bosque; algunas de las cuales son luego reintroducidas en su hábitat natural. Ejemplo de esto último son los yacarés que cada año son liberados en la finca Santo Domingo.

\section{Otros Productos y Roles de los Bosques}

Se destaca el rol educativo que cumple la reserva de Mbopicuá en Fray Bentos, donde maestras con formación especifica en el tema actúan como guias de escolares, enseñándoles la estación de cria de animales autóctonos y el monte ribereño que se extiende sobre la costa del Rio Uruguay. Durante el año 2005, unos 2 mil niños visitaron junto a sus maestras esta reserva.

Desde un punto de vista cultural se enmarcan la conservación de la Tapera de Darwin en el Departamento de Soriano, o las ruinas del saladero de Mbopicuá sobre las costas del Rio Uruguay en las cercanias de Fray Bentos. En ambos casos estos monumentos son gestionados de forma que conserven su fisonomia original, sin permitir su deterioro por actividades humanas asociadas.

\section{Resumen Productos Forestales No Madereros EUFORES}

En el Cuadro $\mathrm{N}^{\circ} 4$ se presenta de manera resumida los productos forestales no madereros de los bosques de la empresa. 


\section{Cuadro $\mathrm{N}^{\circ} 4$.}

RESUMEN DE LOS PFNM- EUFORES

\begin{tabular}{|c|c|c|c|c|}
\hline PRODUCTOS/SERVICIOS & $\begin{array}{l}\text { INGRESOS } \\
\text { DIRECTOS } \\
\text { (US \$/ha) }\end{array}$ & $\begin{array}{l}\text { INGRESOS } \\
\text { INDIRECTOS } \\
\text { (US S/ha) }\end{array}$ & $\begin{array}{c}\text { OTROS } \\
\text { BENEFICIOS }\end{array}$ & $\begin{array}{l}\text { RECOMENDACIONES O } \\
\text { CUIDADOS }\end{array}$ \\
\hline Silvopastoreo bovino & $9,4 / \mathrm{anho}$ & 19 & $\begin{array}{l}\text { Relacionamiento } \\
\text { con productores }\end{array}$ & Protocolo de acción \\
\hline Silvopastoreo ovino & $\cdot$ & 56 & $\begin{array}{l}\text { Relacionamiento } \\
\text { con productores }\end{array}$ & Protocolo de acción \\
\hline Miel & $\begin{array}{l}\text { 72/año (en estudio } \\
\text { de implantación) }\end{array}$ & - & $\begin{array}{l}\text { Relacionamiento } \\
\text { con productores }\end{array}$ & $\begin{array}{l}\text { Protocolo de accion, seria } \\
\text { solo en E grandıs }\end{array}$ \\
\hline Hongos & $\cdot$ & $\cdot$ & $\begin{array}{l}\text { Generación de } \\
\text { mano de obra }\end{array}$ & $\cdot$ \\
\hline Aceites esenciales & $\cdot$ & - & Facilitar $2^{\circ}$ turno & $\begin{array}{l}\text { Se está en fase de } \\
\text { estudio de propuesta }\end{array}$ \\
\hline Fijación de $\mathrm{CO}_{2}$ & $\begin{array}{c}\text { 210iaño } \\
\text { (estimado, no } \\
\text { aplicado aún) }\end{array}$ & $\cdot$ & $\begin{array}{l}\text { La propia fijación } \\
\text { del } \mathrm{CO}_{2}\end{array}$ & - \\
\hline $\begin{array}{l}\text { Conservación. de la } \\
\text { Diversidad Biológlac. }\end{array}$ & - & - & $\begin{array}{l}\text { Mantenimiento de } \\
\text { la biodiversidad }\end{array}$ & $\cdot$ \\
\hline Pedagógico & $\cdot$ & $\cdot$ & $\begin{array}{c}\text { Educacion de } \\
\text { escolares. } \\
\text { relacionamiento }\end{array}$ & - \\
\hline Cultural & $\cdot$ & $\cdot$ & $\begin{array}{l}\text { protección de } \\
\text { monumentos }\end{array}$ & $\cdot$ \\
\hline
\end{tabular}

A modo de ejemplo, el precio de mercado del metro cúbico sólido de $E$. globulus ssp. globulus en pie es de unos 16 US \$, dependiendo de varios parámetros entre los que pueden ser mencionados distancia a puerto (por costos de fletes, ese precio es a distancia media de $100 \mathrm{Km}$.) y estado general del bosque (por costos de cosecha). El precio de la madera puesta en puerto ronda los 37 US $\$ / \mathrm{m}^{3}$ (16 US $\$$ en pie +12 de cosecha +9 de flete). Considerando un turno de 9 años y un crecimiento medio anual de $18 \mathrm{~m}^{3}$, el ingreso por madera es de unos 2.600 US $\$$ al noveno año $\left(9^{\star} 18^{\star} 16\right.$ US $\left.\$\right)$.

\section{CONCLUSIONES Y RECOMENDACIONES}

La posibilidad de realizar actividades alternativas dentro de la masa boscosa a medida que esta se desarrolla, permite la obtención de rentas que posibilitan el prorrateo de gastos e ingresos entre distintos rubros durante el ciclo de crecimiento del Bosque.

Esta generación de ingresos tanto directos como indirectos, se puede dar sin perder de vista el objetivo primario y más importante que para cualquier empresa forestal es el de producir la mayor cantidad de madera en el plazo de tiempo más corto posible.

Se generan beneficios positivos para las comunidades locales, lográndose una mejor y más fluida integración con el medio rural, compatibilizando en tiempo y espacio la producción maderera con alguna de las actividades agropecuarias tradicionales. 
Las funciones ecológicas que cumplen los bosques son muy importantes para la sociedad en su conjunto, de modo que potenciar el desarrollo de las mismas es trascendente para generaciones actuales y futuras.

Las distintas funciones sociales que cumplen los bosques son aprovechadas por gran parte de la sociedad (recreación, conservación, etc.) sirviendo de interacción con el medio y ayudando a concientizar al ser humano de lo importante del cuidado del medio ambiente todo y de los bosques en particular.

Los procesos de certificación del origen de las maderas procedentes de determinados bosques son muy importantes tanto para informar a los consumidores del origen de la misma como para promover la ordenación sostenible de los bosques.

Como recomendaciones del estudio se puede anotar las siguientes:

Para gestionar los bosques desde un punto de vista de uso múltiple es imprescindible la realización de Planes de Manejo, como forma de ordenar el bosque y maximizar los potenciales usos del mismo durante el turno de la masa. Un Plan de Manejo basado en el principio de uso múltiple, deberá contemplar el desarrollo integral de todos los recursos que existen en el área de una manera armónica, con los fines de proporcionar los productos y servicios de acuerdo con las necesidades económicas, sociales y culturales de la gente.

Es fundamental la correcta elección de los usos a llevar a cabo, no pudiendo ser competitivos, o sea el uso alternativo del bosque no puede afectar negativamente el desarrollo de la masa boscosa.

Toda intervención en los bosques por usos múltiples (pastoreo, aceites esenciales, colmenas, otros) debe llevarse a cabo a través de protocolos de acción, como forma de evitar posibles daños a los árboles.

Seria importante evaluar y cuantificar en trabajos sucesivos los usos alternativos en masas boscosas con otros fines industriales (como aserrio), de rotación más prolongada, en donde la aplicación de regimenes de poda y raleo proporcionan más luz y espacio y muy probablemente favorecerán la integración de usos adicionales como la ganadería u otros.

\section{REFERENCIAS}

Deschamps, J. R., 2002. Hongos Silvestres Comestibles del MERCOSUR con Valor Gastronómico: Documento de Trabajo, Departamento de Investigación, Área de Estudios Agrarios, Universidad de Belgrano, Buenos Aires.

Empresa Secco Hnos., 1998. Evaluación de Manejo Silvopastoril. Experiencia Nacional, Informe. Eufores. Vida entre Palmeras. Flora y Fauna de Santo Domingo.

Prigioni, C.; Villalba, J., 2005. Flora y Fauna en Predios de la Empresa Eufores. Informe Revista CHILE Forestal. 1976; Año 2, No 12, Chile. 
Rowe, R. S.; Mc Cormack, R. J., 1968. Silvicultura y Uso Múltiple de la Tierra, India.

Sans, C., 1992. Uso recreativo del Bosque. Notas Técnicas $N^{\circ} 19$, Montevideo, Uruguay.

V Jornadas Técnicas,1989. Uso Múltiple del bosque y Sistemas Agroforestales, Misiones, Argentina.

Stevens, James A. y Montgomery Claire A., 2002. Understanding the Compatibility of Multiple Uses on Forest Land: A Survey of Multiresource Research with Application to the Pacific Northwest; United States Department of Agriculture, Forest Service, General Technical Report. 


\section{REGLAMENTO DE PUBLICACION}

CIENCIA E INVESTIGACION FORESTAL es una publicación técnica, cientifica, arbitrada y seriada del Instituto Forestal de Chile, en la que se publica trabajos originales e inéditos, con resultados de investigaciones $o$ avances de estas, realizados por sus propios investigadores y por profesionales del sector, del pais o del extranjero, que estén interesados en difundir sus experiencias en áreas relativas a las múltiples funciones de los bosques, en los aspectos económicos, sociales y ambientales. Consta de un volumen por año el que a partir del año 2007 estará compuesto por tres números (abril, agosto y diciembre) y ocasionalmente un número especial.

La publicación cuenta con un Consejo Editor institucional que revisa en primera instancia los trabajos presentados y está facultado para aceptarlos, rechazarlos o solicitar modificaciones a los autores. Dispone además de un selecto grupo de profesionales externos y de diversos paises, de variadas especialidades, que conforma el Comité Editor. De acuerdo al tema de cada trabajo, estos son enviados por el Editor a al menos tres miembros del Comité Editor para su calificación especializada. Los autores no son informados sobre quienes arbitran los trabajos.

La revista consta de dos secciones; Artículos Técnicos y Apuntes, puede incluir además articulos de actualidad sectorial en temas seleccionados por el Consejo Editor o el Editor.

- Artículos: Trabajos que contribuyen a ampliar el conocimiento cientifico o tecnológico, como resultado de investigaciones que han seguido un método cientifico.

- Apuntes: Comentarios o análisis de temas particulares, que presenten enfoques metodológicos novedosos, representen avances de investigación, informen sobre reuniones técnicas o programas de trabajo y otras actividades de interés dentro del sector forestal o de disciplinas relacionadas. Los apuntes pueden ser también notas bibliográficas que informan sobre publicaciones recientes, en el pais o en el exterior, comentando su contenido e interés para el sector, en términos de desarrollo cientifico y tecnológico o como información básica para la planificación y toma de decisiones.

\section{ESTRUCTURA DE LOS TRABAJOS}

\section{Articulos}

Los trabajos presentados para esta sección deberán contener Resumen, Summary. Introducción, Objetivos, Material y Método, Resultados, Discusión, Conclusiones, Reconocimientos (optativo) y Referencias. En casos muy justificados Apéndices y Anexos.

El título del trabajo debe ser representativo del efectivo contenido del artículo y debe ser construido con el minimo de palabras. 
Resumen: Breve descripción de los objetivos, de la metodologia y de los principales resultados y conclusiones. Su extensión máxima es de una página y al final debe incluir al menos tres palabras clave que faciliten la clasificación bibliográfica del artículo. El Summary es evidentemente la versión en inglés del Resumen. No deben incluir referencias, cuadros ni figuras.

Objetivos: Breve enunciado de los fines generales del artículo o de la linea de investigación a que corresponda y definición de los objetivos específicos del artículo en particular.

Material y Método: Visión clara de la metodologia aplicada y, cuando corresponda, de los materiales empleados en las investigaciones o estudios que dan origen al trabajo. Si la metodologia no es original se deberá citar claramente la fuente de información. Este punto puede incluir Cuadros y Figuras, siempre y cuando su información no resulte repetida con la entregada en texto.

Resultados: Punto reservado para todos los resultados obtenidos, estadisticamente respaldados cuando corresponda, y asociados directamente a los objetivos especificos antes enunciados. Puede incluir Cuadros y Figuras indispensables para la presentación de los resultados o para facilitar su comprensión, igual requisito deben cumplir los comentarios que aqui se pueda incluir.

Discusión y Conclusiones: Análisis e interpretación de los resultados obtenidos, sus limitaciones y su posible trascendencia. Relación con la bibliografia revisada y citada. Las conclusiones destacan lo más valioso de los resultados y pueden plantear necesidades consecuentes de mayor investigación o estudio o la continuación lógica de la linea de trabajo.

Reconocimientos: Punto optativo, donde el autor si lo considera necesario puede dar los créditos correspondientes a instituciones o personas, que han colaborado en el desarrollo del trabajo o en su financiamiento. Obviamente se trata de un punto de muy reducida extensión.

Referencias: Identificación de todas las fuentes citadas en el documento, no debe incluir referencias que no han sido citadas en texto y deben aparecer todas aquellas citadas en este.

Apéndices y Anexos: Deben ser incluidos sólo si son indispensables para la comprensión del trabajo y su incorporación se justifica para reducir el texto. Es preciso recordar que los Apéndices contienen información o trabajo original del autor, en tanto que los Anexos contienen información complementaria que no es de elaboración propia.

\section{Apuntes}

Los trabajos presentados para esta sección tienen en principio la misma estructura descrita para los articulos, pero en este caso, según el tema, grado de avance de la investigación o actividad que los motiva, se puede adoptar una estructura más simple, 
obviando los puntos que resulten innecesarios. En su primera página arriba tendrán el titulo del trabajo y la identificación de los autores, institución y pais.

\section{PRESENTACION DE LOS TRABAJOS}

La Revista acepta trabajos en español y ocasionalmente en inglés o portugués, redactadas en lenguaje universal, que pueda ser entendido no sólo por especialistas, de modo de cumplir su objetivo de transferencia de conocimientos y difusión al sector forestal en general. No se acepta redacción en primera persona.

Formato tamaño carta $(21,6 \times 27,9 \mathrm{~cm})$, márgenes $2,5 \mathrm{~cm}$ en todas direcciones, espacio simple y un espacio libre entre párrafos. Letra arial 10. Un tab (5 espacios) al inicio de cada párrafo. No numerar páginas. Extensión máxima trabajos 25 carillas para articulos y 15 para Apuntes. Justificación ambos lados.

Primera página incluye título en mayúsculas, negrita, centrado, letra 12, una línea, eventualmente dos como máximo. Dos espacios bajo éste: Autor (es), minúsculas, letra 10 y llamado a pie de página indicando Institución, país y correo electrónico en letra 8. Dos espacios más abajo el Resumen y, si el espacio resulta suficiente, el Summary. Si no lo es, página siguiente igual que anterior, el Summary.

Título puntos principales (Resumen, Summary, Introducción, Objetivos, etc) en mayúsculas, negrita, letra 10, margen izquierdo. Sólo para Introducción usar página nueva, resto puntos principales seguidos, separando con un espacio antes y después de cada uno. Titulos secundarios en negrita, minúsculas, margen izquierdo. Títulos de tercer orden minúsculas margen izquierdo. Si fuesen necesarios títulos de cuarto orden, usar minúsculas, un tab (5 espacios) y anteponer un guión y un espacio. Entre sub títulos y párrafos precedente y siguiente un espacio libre. En sub títulos con más de una palabra usar primera letra de palabras principales en mayúscula. No numerar puntos principales ni sub títulos.

Nombres de especies vegetales o animales: Vulgar o vernáculo en minúsculas toda la palabra, seguido de nombre en latin o científico entre paréntesis, en cursiva (no negrita), minúsculas y primera letra del género en mayúsculas. Ej. pino o pino radiata (Pinus radiata).

Citas de referencias bibliográficas: Sistema Autor, año. Ejemplo en citas en texto; De acuerdo a Rodríguez (1995) el comportamiento de...., o el comportamiento de... (Rodríguez, 1995). Si son dos autores; De acuerdo a Prado y Barros (1990) el comportamiento de .... o el comportamiento de ... (Prado y Barros, 1990). Si son más de dos autores; De acuerdo a Mendoza et al. (1990), o el comportamiento ... (Mendoza et al., 1990).

En el punto Referencias (no Bibliografia) deben aparecer en orden alfabético por la inicial del apellido del primer autor, letra 8, todas las referencia citadas en texto y sólo estas. En este punto la identificación de la referencia debe ser completa: Autor (es), año. En negrita, minúsculas, primeras letras de palabras en mayúsculas y todos los autores en el orden que aparecen en la publicación, aqui no se usa et al. A continuación, en minúscula y letra 8 , primeras letras de palabras principales en mayúscula, título completo y exacto de la 
publicación, incluyendo institución, editorial y otras informaciones cuando corresponda. Margen izquierdo con justificación ambos lados. Ejemplo:

En texto: (Yudelevich et al., 1967) o Yudelevich et al. (1967) señalaron ...

En referencias:

Yudelevich, Moisés; Brown, Charles y Elgueta, Hernán, 1967. Clasificación Preliminar del Bosque Nativo de Chile. Instituto Forestal. Informe Técnico Nº 27. Santiago, Chile.

Cuadros y Figuras: Numeradas correlativamente, no deben repetir información dada en texto. Sólo se aceptan cuadros y figuras, no asi tablas, gráficos, fotos u otras denominaciones. Toda forma tabulada de mostrar información se presentará como cuadro y al hacer mención en texto (Cuadro $N^{\circ} 1$ ). Gráficos, fotos y similares serán presentadas como figuras y al ser mencionadas en texto (Figura $N^{\circ} 1$ ). En ambos casos aparecerán enmarcados en linea simple y centrados en la página. En lo posible su contenido escrito, si lo hay, debe ser equivalente a la letra arial 10 u 8 y el tamaño del cuadro o figura proporcionado al tamaño de la página. Cuadros deben ser titulados como Cuadro $\mathrm{N}^{\circ}$, minúsculas, letra 8 , negrita centrado en la parte superior de estos, debajo en mayúsculas, negritas letra 8 y centrado el título (una linea en lo posible). Las figuras en tanto serán tituladas como Figura $\mathrm{N}^{\circ}$, minúscula, letra 8, negrita, centrado, en la parte inferior de estas, y debajo en mayúsculas, letra 8 , negrita, centrado, el titulo (una linea en lo posible). Cuando la información proporcionada por estos medios no es original, bajo el marco debe aparecer entre paréntesis y letra 8 la fuente o cita que aparecerá también en referencias. Si hay simbolos u otros elementos que requieren explicación, se puede proceder de igual forma que con la fuente.

Se aceptan fotos en blanco y negro, eventualmente en colores, siempre que reúnan las caracteristicas de calidad y resolución que permitan su impresión.

Abreviaturas, magnitudes y unidades deben estar atenidas a la Norma Nch 30 del Instituto Nacional de Normalización (INN). Se empleará en todo caso el sistema métrico decimal. Al respecto es conveniente recordar que la unidades se abrevian en minúsculas, sin punto, con la excepción de litro $(L)$ y de aquellas que provienen de apellidos de personas como grados Celsius $\left({ }^{\circ} \mathrm{C}\right)$. Algunas unidades de uso muy frecuente: metro, que debe ser abreviado $\mathrm{m}$ y no M. m. MT MTS $\mathrm{mt}$ mts o mtrs y otras formas como a menudo se ve en las carreteras y otros lugares; metro cúbico $\mathrm{m}^{3}$, metro ruma $\mathrm{mr}$; o hectáreas ha y no HTA HAS há o hás.

Llamados a pie de página: Cuando estos son necesarios, serán numerados en forma correlativa para cada página, no de 1 a n a lo largo del trabajo. Aparecerán al pie en letra 8.

Archivos protegidos, sólo lectura o en PDF serán rechazados de inmediato porque no es posible editarlos. La Revista se reserva el derecho de efectuar todas las modificaciones de carácter formal que el Comité Editor o el Editor estimen necesarias o convenientes, sin consulta al autor. Modificaciones en el contenido evidentemente son consultadas por el Editor al autor, si no hay acuerdo se recurre nuevamente al Consejo Editor o los miembros de este que han participado en el arbitraje o calificación del trabajo. 


\section{ENVIO DE TRABAJOS}

Procedimiento electrónico. En general bastará enviar archivo Word, abierto al Editor sbarros@infor.gob.cl

Cuadros y figuras ubicadas en su lugar en el texto, no en forma separada. El Editor podrá en algunos casos solicitar al autor algún material complementario en lo referente a cuadros y figuras (archivos Excel, imágenes, figuras, fotos, por ejemplo).

El autor deberá indicar si propone el trabajo para Articulo o Apunte y asegurarse de recibir confirmación de la recepción conforme del trabajo por parte del Editor. Respecto del peso de los archivos, tener presente que $1 \mathrm{Mb}$ es normalmente el límite razonable para los adjuntos por correo electrónico. No olvidar que las imágenes son pesadas, por lo que siempre al ser pegadas en texto Word es conveniente recurrir al pegado de imágenes como JPEG o de planillas Excel como Metarchivo Mejorado.

En un plazo de 30 dias desde la recepción de un trabajo el Editor informará al autor principal sobre su aceptación (o rechazo) en primera instancia e indicará (condicionado al arbitraje del Comité Editor) el Volumen y Número en que el trabajo seria incluido. Posteriormente enviará a Comité Editor y en un plazo no mayor a 3 meses estará sancionada la situación del trabajo propuesto. Si se mantiene la información dada por el Editor originalmente, el trabajo es aceptado como fue propuesto (Articulo o Apunte) y no hay observaciones de fondo, el trabajo es editado y pasa a publicación cuando y como se informó al inicio. Si no es asi, el autor principal será informado sobre cualquier objeción, observación o variación, en un plazo total no superior a 4 meses. 


\section{CIENCIA E INVESTIGACION FORESTAL}

CONTENIDO

ARTICULOS

ANTECEDENTES PARA EL USO DEL MONTE BAJO DE EUcalyptus globulus EN CHILE. Juan Carlos Pinilla, Maria Paz Molina y Mauricio Aguilera. Chile.

ANALISIS ECONOMICO DE OPCIONES PRODUCTIVAS PARA PLANTACIONES DE EUCalyptUS nitens EN EL SUR DE CHILE. Juan Carios Valencia y Jorge Cabrera. Chile

SILVICULTURE OF EUCALYPT PLANTATIONS IN SOUTHERN AUSTRALIA FOR HIGH-VALUE SOLID WOOD PRODUCTS. Tom Baker y Peter Volver. Australia

REQUERIMIENTOS DE INNOVACIÓN ESTRATÉGICA COMPETITIVA PARA EL SECTOR FORESTAL. Ignacio Cerda, Carlos Olavarria, Ammando Sanhueza y Omar Villanueva O. Chile.

ESTUDIOS DE MERCADO: EL CASO DE LA MADERA DE CANELO EN ESTADOS UNIDOS Y EUROPA. Jorge Cabrera. Chile.

CARACTERIZACIÓN AMBIENTAL Y PRODUCTIVA DE RODALES FORESTALES DE CASTAÑO EN CHILE. Susana Benedettiy Jaime Saavedra. Chile

EVALUACIÓN DELAPRODUCCIÓN Y PRODUCTIVIDAD EN BIOMASA AÉREA DE BOLDO (Peumus boldus Mol.) EN UN BOSQUE ESCLEROFILO. Sergio Donoso y Leonardo Duran. Chile.

ENSAYOS DE RECUPERACION DE FORMACIONES NATURALES DE GUAYACAN. Antonio Vita. Chile

\section{APUNTES}

EL ENFOQUE ECOSISTEMICO EN EL MANEJO FORESTAL EN CENTROAMERICA. José Joaquin Campos, Roger Villalobos y Bastiaan Louman. Costa Rica

EL PAGO POR SERVICIOS AMBIENTALES, CONCEPTOS Y MERCADOS. Jorge Cabrera. Chile. PRODUCTOS FORESTALES NO MADEREROS DEL BOSQUE: UN SIGNIFICATIVO APORTE ECONOMICO A LA EMPRESA FORESTAL. Alejandro González y Carolina Sans. Uruguay.

\section{REGLAMENTO DE PUBLICACION}

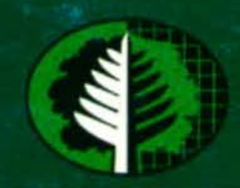

